\section{Safety cabinets and AIDS}

SIR - Many laboratory workers will be dismayed at the recent recommendation from the Advisory Committee on Dangerous Pathogens (ACDP) regarding the use of microbiological safety cabinets for the acquired immune deficiency syndrome (AIDS) agent human T-cell lymphotropic virus type III (HTLV-III). In this ACDP report ${ }^{1}$ it is stated: "It is now clear that infection with HTLV-III may result in a fatal disease for which there is no effective prophylaxis or treatment. While there is still uncertainty about all the possible routes of transmission in the laboratory environment, care must be taken to avoid the dispersal of aerosols and for some work microbiological safety cabinets will be required. Because there are reservations about the level of operator protection which can be maintained by Class II cabinets under working conditions, for the time being, they must not be used for work with materials which contain the virus."

In many respects this conflicts with paragraph 5, Appendix A of the ACDP document Categorisation of pathogens according to hazard and categories of containment again published in $1984^{2}$, only a few months before the AIDS recommendations. This appendix states that "In certain conditions some Class II cabinets will provide a protection factor of the same order as Class I cabinets (that is, a factor of $10^{5}$ or better. BS 5726: $1979^{3}$ ).

If it can be shown by in-use tests that this level is achieved consistently (as demonstrated by tests carried out at regular intervals, the frequency of which will depend on use) and provided that the local safety arrangements will allow, a Class II cabinet may be used for some work with group 3 pathogens where protection of the work is essential.

In the six years since BS 5726 was published, many laboratories have invested heavily in both Class I and II cabinets that meet the operator protection requirements of the standard. Cabinet manufacturers have responded well to these requirements with the result that many open-fronted cabinets can consistently provide more than the minimum protection factor of $10^{5}$. In addition, there has been a great improvement in the routine maintenance and certification of such cabinets. Many institutions now require certification to the filtration and containment requirements of the standard to be obtained twice per year for each cabinet.

The latest ACDP recommendations on the use of AIDS material in safety cabinets are questionable on two counts. In the first place they indict Class II cabinets in favour of Class I types and in so doing ignore the fact that Class I types are at least as easily disturbed by operator movements, by ventilation systems, by door movements and by people circulating within the laboratory. It is quite possi- ble to reduce operator protection factors by one to two orders of magnitude by poor operator technique and lack of correct discipline.

Secondly, the recommendations totally disregard the current performance of many new Class II type cabinets which can produce consistent operator protection factors up to and beyond $10^{6}$. It has to be remembered that BS 5726 makes no distinction between the operator protection of Class I and II cabinets - both must have factors of at least $10^{5}$

If there is so much uncertainty about the virulence of HTLV-III, then the very sensible procedures regarding the testing of operator protection factor initially outlined by ACDP for Class II cabinets ${ }^{2}$ should be just as vigorously implemented for Class I types. As the weight of evidence does not favour transmission of HTLV by the airborne route, it is difficult to understand why Class I cabinets are allowed whilst similarly performing Class II cabinets are disallowed. Some of the work of this laboratory indicates that a number of the recently produced high performance Class II cabinets do, in fact, have higher nominal protection factors

\section{Life and death}

SIR - Rapid innovations in the biological sciences and technology are creating new and difficult ethical problems, as is evident to readers of Nature from numerous articles and letters. Most prominent are problems concerned with the early phase of the human life cycle. (See for example recent letters to Nature on the question "When life begins", Nature 314, 492; 1985.) The "rights" of a human zygote, embryo and fetus, but for some reason not gametes, seem to evoke strong emotions.

New problems are also arising about when life ends. Problems of organ exchange necessitate a legal definition of the death of an individual.

At another level, what should be the status of human cells cultivated in vitro? These cells, in common with zygotes, have the potential, theoretical at the moment, to be regenerated if properly nurtured.

Further problems are now raised with the news of cloning of DNA extracted from an Egyptian mummy (Nature 314, 576 and $644 ; 1985)$.

The unique genome of a human being apparently does not die when a person stops breathing or when electrical brain activity ceases.

The DNA molecules can be extracted and under proper conditions can be replicated. Thus by at least some definition of living matter the DNA is "alive". If the DNA is still alive, should we not change our accepted procedures of disposing of human corpses?

I suggest that the procedure of crema() 1985 Nature Publishing Group and are more resistant to disturbances than many Class I cabinets. Much of this cabinet evaluation work has been published in the scientific literature ${ }^{5}$ and has formed the basis for containment policy in the Medical Research Council. It is naive to think that tissue culture work will always escape contamination in Class I cabinets or that they are intrinsically safer than Class II types. The banning of Class II cabinets by ACDP for AIDS work is inconsistent with their other recommendations and will cause grave difficulties for laboratory workers who require both operator and product protection without the difficulties associated with Class III cabinets. On this aspect of containment the ACDP committee should think again. $\quad$ R. P. Clark

Laboratory for Aerobiology,

Clinical Research Centre,

Watford Road, Harrow,

Middlesex HA1 $3 U J, U K$

1. Advisory Committee on Dangerous Pathogens. Acquired Immune Deficiency Syndrome (AIDS) - Interim Guide lines. (Health and Safety Executive. London 1984).

2. Advisory Committee on Dangerous Pathogens. Categorisa tion of Pathogens According to Hazard and Categories of Containment (Health and Safety Executive, London 1984). BS 5726: Specification for Microbiological Safety Cabinets (British Standards Institution, London, 1979).

4. Clark, R. P. Occupational Hygiene Monograph No. 9 (Science Reviews. Northwood, 1983); Phil. Trans. R. Soc Lond. B302, 593-604 (1983).

5. Clark, R. P. \& Hill, J. J. clin. Path. 34, 12, 1404 (1981).

tion, sometimes associated with the saving of the ashes as a memorial, is improper. Instead it would make much more "biological sense" to save at least a sample of DNA from the deceased.

I envision "mausoleums" where sealed test tubes containing these DNA samples will be kept as an appropriate memorial to individuals. With the rapid progress of biotechnology, the potential for "resurrection" of at least some on one's traits is not remote.

Aharon Gibor

Biology Department,

University of California, Santa Barbara, Santa Barbara, California 93106, USA

\section{Cows and goats}

Sir - While Andrew Hill (Nature 315, $222 ; 1985)$ shows deep understanding of the evolution of early African Hominoidea, his knowledge of Kalenjin nomenclature appears limited.

John Kimengich is surely John Kimngetich, which in Kalenjin means "born between 10 and 11 a.m. when the cows leave the cattle enclosure".

I am sure Dr Hill appreciates how in Kalenjin, as in English, omitting certain letters, for example the "o" from hominoid, can dramatically alter the sense.

Monique Borgerhoff Mulder (born between 9 and 10 a.m. when the goats go out, also known as Chemngeno)

Tabarit village,

PO Gorgor,

Sotik,

Kericho, Kenya 